\title{
Automated measurement of plasma viscosity by capillary viscometer
}

\author{
B M COOKE, J STUART Department of Haematology, Medical School, University of Birmingham
}

SUMMARY Plasma viscosity has several advantages over the erythrocyte sedimentation rate as a measurement of an acute phase response of more than 24 hours' duration. A new capillary viscometer (Coulter Viscometer II), which gives an automated measurement of plasma viscosity, was compared with the selected manual method (Harkness viscometer) of the International Committee for Standardization in Haematology. Automated measurement of plasma viscosity at $25^{\circ} \mathrm{C}$ showed close correlation $(r=0.979, p<0.002)$ with the selected method for 160 specimens of plasma. Satisfactory precision both within batch and between batch (coefficients of variation of $1.7 \%$ or less) was obtained at viscosity values up to $5.7 \mathrm{mPa} \cdot \mathrm{s}$. There was no detectable carry over between samples and viscosity values were corrected adequately for ambient temperature for the range $15-32^{\circ} \mathrm{C}$. Careful daily cleaning was required to prevent accumulation of protein within the automatic sampling valve of the instrument. Automated measurement of plasma viscosity is an attractive alternative to measurement of the erythrocyte sedimentation rate.

Tissue damage induces a local inflammatory response that in turn stimulates, through interleukin 1 and other mediators, an increase in hepatic synthesis of several acute phase proteins.' Quantitative assay of these acute phase proteins in serum is useful for diagnosing and monitoring an inflammatory response. ${ }^{2}$ In the early stages of inflammation ( $<24$ hours), assay of the fast responding $\mathrm{C}$ reactive protein is the test of choice, whereas the more complex hyperproteinaemia of the later stages of inflammation ( $>24$ hours) should be measured by tests such as the erythrocyte sedimentation rate (ESR) and plasma viscosity, which are sensitive to the combined effect of multiple proteins. ${ }^{3}$

Measurement of plasma viscosity has several advantages over measurement of ESR. ${ }^{2-6}$ These include independence from the effects of anaemia, polycythaemia, and erythrocyte deformability; a reference range that is independent of sex and less dependent on age; a shorter assay time; the facility to store plasma for subsequent assay; and the potential for calibration, quality control, and automation. The selected method of the International Committee for Standardization in Haematology for measuring plasma viscosity was that of Harkness, and was based on a manually operated, temperature controlled, capillary viscometer. ${ }^{8}$ An automated capillary viscometer incorporating the Harkness principle is now commercially available, and we have compared its

Accepted for publication 19 May 1988 performance with that of the selected method of the International Committee.

\section{Patients and methods}

Venous blood, anticoagulated with the dipotassium salt of ethylenediamine tetra-acetic acid $(1.5-2.0 \mathrm{mg} /$ $\mathrm{ml}$ ) was collected from healthy controls, hospital patients with an acute phase or chronic phase inflammatory response, and patients with paraproteinaemia. Blood samples were centrifuged at $1500 \mathrm{~g}$ for 10 minutes within five hours of venepuncture, and the supernatant plasma was stored at room temperature in a capped plastic tube until assayed (within two hours).

Manual viscosity measurements were made according to the recommendations of the International Committee for Standardization in Haematology using a Harkness capillary viscometer (Coulter Electronics Ltd, Luton) at $25^{\circ} \mathrm{C}$. Automated measurements were made by the new Viscometer II (Coulter Electronics Ltd). The latter comprises a glass capillary tube $\mathbf{0 . 3 8} \mathrm{mm}$ in internal diameter and 200 $\mathrm{mm}$ long through which a plasma sample of $0.5 \mathrm{ml}$ is forced at a constant positive pressure of $17 \cdot 2 \mathrm{kPa}$. Plasma viscosity is proportional to its flow time through the capillary. Readings are made at ambient temperature and corrected to a viscosity value at 25 or $37^{\circ} \mathrm{C}$, whichever is preferred.

The instrument may be used as a manual viscometer, the results being shown on a vacuum fluorescent display. Alternatively, the optional 20 
sample carousel and printer give an automated measure of viscosity.

\section{Results}

The Viscometer II required a 30 minute warm up period during which it automatically primed itself with Viscometer II rinse fluid (Coulter Electronics Ltd). Calibration was also automatic using the manufacturer's Viscometer II Calibrator. The viscosity of high and low control reagents (Viscometer II Hi/Lo Control, Coulter Electronics Ltd) was measured with each batch of test plasmas as a check of calibration and to detect drift. Recalibration was usually required once or twice a week. The manufacturer's stated values for the viscosity of the Viscometer II Calibrator and $\mathrm{Hi} / \mathrm{Lo}$ Control reagents were checked using the Harkness viscometer. The results (table 1) show close agreement with the stated values.

All viscosity measurements with the Viscometer II were corrected by the instrument to a selected temperature of $25^{\circ} \mathrm{C}$ to permit comparison with the Harkness viscometer, the water bath of which was maintained at $25^{\circ} \mathrm{C}$. To check the instrument's ability to correct to $25^{\circ} \mathrm{C}$, the Viscometer II was placed in a temperature controlled room at $15^{\circ} \mathrm{C}, 25^{\circ} \mathrm{C}$, and then $32^{\circ} \mathrm{C}$. Viscosity measurements were then made on 10 aliquots of the manufacturer's low control reagent, calibrator, and high control reagent. The mean results (table 2) show adequate correction of the viscosity readings at $15^{\circ} \mathrm{C}$ and $32^{\circ} \mathrm{C}$ to within $1.7 \%$ of the measured viscosity at $25^{\circ} \mathrm{C}$.

Table 1 Viscosity values ( $\mathrm{mPa} \cdot \mathrm{s}$ ) at $25^{\circ} \mathrm{C}$ for control reagents as stated by manufacturer and measured by Harkness viscometer

\begin{tabular}{|c|c|c|c|}
\hline & $\begin{array}{l}\text { Low control } \\
\text { reagent }\end{array}$ & Calibrator & $\begin{array}{l}\text { High control } \\
\text { reagent }\end{array}$ \\
\hline \multirow{3}{*}{$\begin{array}{l}\text { Manufacturer's } \\
\text { stated range } \\
\text { Mean viscosity } \\
\text { (Harkness; } \\
\text { n = 10) } \\
95 \% \text { Confidence } \\
\text { interval }\end{array}$} & $1 \cdot 17-1 \cdot 23$ & $1.58-1.62$ & $1.96-2.04$ \\
\hline & $1 \cdot 20$ & 1.60 & 2.02 \\
\hline & 1.196 to 1.204 & 1.596 to 1.604 & 2.015 to 2.025 \\
\hline
\end{tabular}

Plasma samples from 160 hospital patients were assayed in parallel using a Viscometer II and a Harkness viscometer at $25^{\circ} \mathrm{C}$ and showed a close linear association $(r=0.979$, gradient $=0.969$, intercept $=0.058$ ). The correlation for 50 of these patients, selected to cover the viscosity range 1.38 to $5.02 \mathrm{mPs} \cdot \mathrm{s}$, is shown in fig 1 .

Within batch precision was determined at four levels of viscosity using plasma from four patients. The coefficients of variation for 10 aliquots from each specimen of plasma were $0.5 \%$ at 1.07 $\mathrm{mPa} \cdot \mathrm{s}$ (plasma diluted with $3 \cdot 1 \% \mathrm{w} / \mathrm{v}$ trisodium citrate), $0.6 \%$ at $1.64 \mathrm{mPa} \cdot \mathrm{s}, 1.3 \%$ at $3.78 \mathrm{mPa} \cdot \mathrm{s}$, and $1.7 \%$ at $5.66 \mathrm{mPa} \cdot \mathrm{s}$. Between batch precision was determined at three measurements of viscosity using the manufacturer's low control reagent, calibrator, and high control reagent. The coefficients of variation for 10 aliquots of each reagent were $0.53 \%$ at 1.20 $\mathrm{mPa} \cdot \mathrm{s}, 0.55 \%$ at $1.60 \mathrm{mPa} \cdot \mathrm{s}$, and $0.58 \%$ at $2.00 \mathrm{mPa} \cdot \mathrm{s}$.

A specimen of normal plasma was diluted, using $3 \cdot 1 \% \mathrm{w} / \mathrm{v}$ trisodium citrate to give a low viscosity

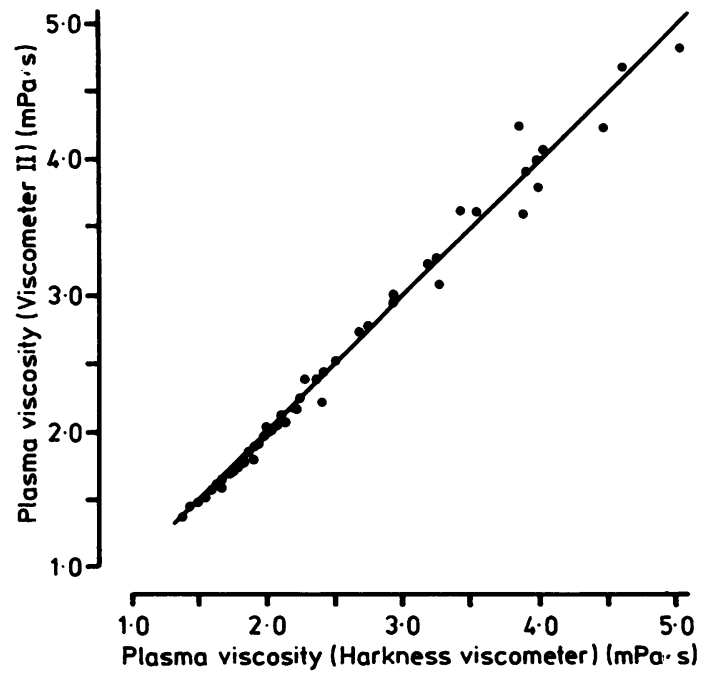

Fig 1 Scattergram with regression line showing correlation $(r=0.994 ; p<0.002)$ between plasma viscosity values at $25^{\circ} \mathrm{C}$ measured with a Harkness viscometer and a Viscometer $I I(n=50)$.

Table 2 Mean viscosity values measured by Viscometer II at three temperatures, and expressed as $\mathrm{mPa} \cdot \mathrm{s}$ at $25^{\circ} \mathrm{C}$, for low control reagente. calibrator, and high control reagent

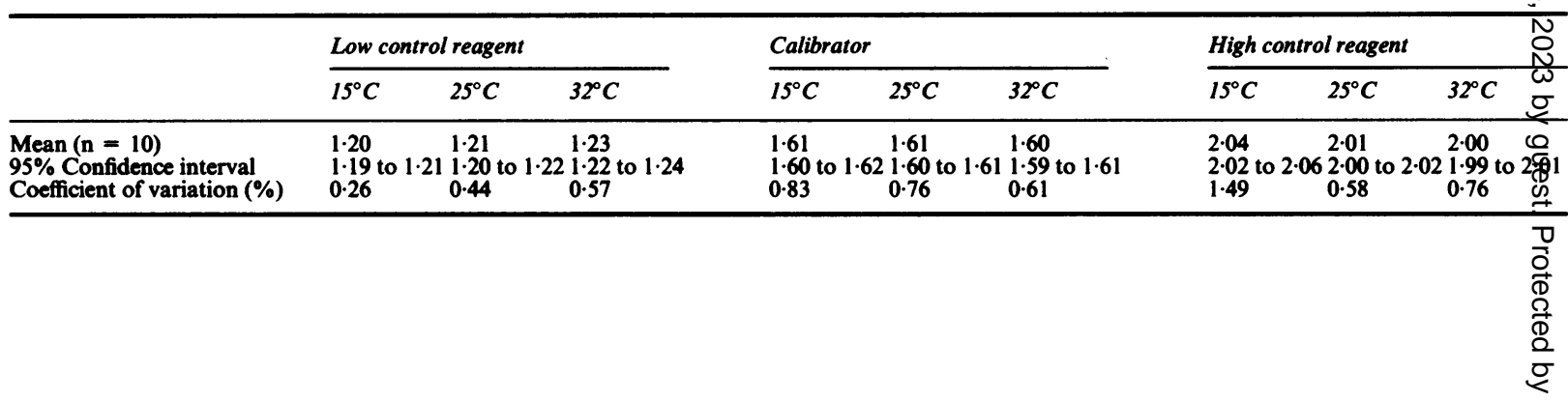



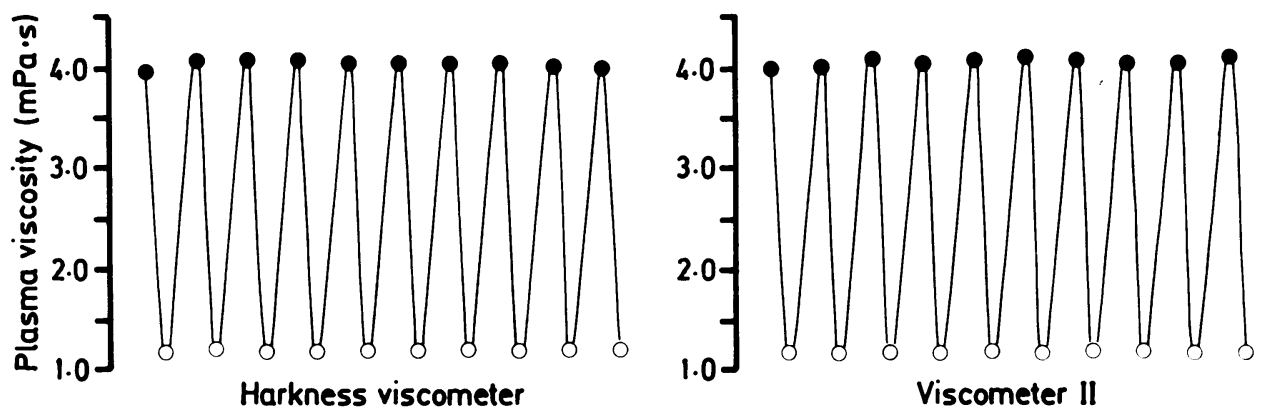

Fig 2 Ten alternate measurements at $25^{\circ} \mathrm{C}$ of plasma samples of high (4.07 mPa.s; ) and low (1.15 mPa.s; O) viscosity, measured with a Harkness viscometer and a Viscometer II.

(mean $1 \cdot 15 \mathrm{mPa} \cdot \mathrm{s}, 95 \%$ confidence interval $1 \cdot 14$ to $1 \cdot 16$, for 10 replicate measurements). A plasma of high viscosity (mean $4.07 \mathrm{mPa} \cdot \mathrm{s}, 95 \%$ confidence interval 4.05 to 4.09 , for 10 measurements) was obtained from a patient with an IgM paraprotein. When the two plasmas were assayed alternately, there was no evidence of carry over (fig 2) for either instrument.

The Viscometer II required $\mathbf{3 0}$ minutes to warm up, five minutes to calibrate, and three minutes to check calibration using low and high control reagents. The instrument has recently been modified so that recalibration is not required every time it is switched on. A loaded carousel comprising 20 samples of plasma, both normal and abnormal, took 20-22 minutes before a print out of the results was available. For a single measurement of plasma viscosity, using a calibrated instrument, it required an average of four minutes to measure the two control reagents and one test specimen.

The water bath of the Harkness viscometer required an average of 15 minutes to warm from ambient temperature to $25^{\circ} \mathrm{C}$, and one to two minutes to check calibration using $3.6 \% \mathrm{w} / \mathrm{v}$ aqueous sodium chloride. Thereafter the 20 specimens (as above) were processed manually in 15 minutes. For a single measurement, using a warm instrument, it required an average of two minutes to measure the viscosity of sodium chloride and one test specimen.

Use of both instruments entails the biohazard associated with centrifugation and transfer of plasma either to the carousel of the Viscometer II or to a plastic test tube before testing in the Harkness viscometer. The manufacturer's original recommendation for cleaning the Viscometer II required aspiration of five samples of hypochlorite solution $(2 \%$ available chlorine) followed by 15 samples of distilled water. We found this to be inadequate as protein build up occurred within the sampling valve over one to two months. Aspiration of 10 samples of hypochlorite solution ( $4 \%$ available chlorine), followed by 10 samples of distilled water at the end of the working day, was sufficient to overcome this problem. The operator's manual has been modified accordingly.

The Viscometer II is designed to measure plasma viscosity in the range $1-5 \mathrm{mPs} \cdot \mathrm{s}$; viscosity results between $5-7 \mathrm{mPa} \cdot \mathrm{s}$ are displayed but with a cautionary symbol. Dilution of plasma with a viscosity of more than $7 \mathrm{mPs}$-s does not overcome this limitation as the association between viscosity and dilution is not linear.

Running costs for centrifuge tubes, sample cups, calibrator and control reagents, rinse fluid, paper for the printer, and disposable pipettes were $11 \mathrm{p}$ a test for a batch of 20 tests, and 88p a single test at the time of writing. If the costs of the initial calibration of the instrument were excluded, the cost fell to $9 p$ a test for a batch of 20 tests and to $42 p$ a single test.

\section{Discussion}

Quantitative measurement of acute phase proteins is of value in diagnosing and monitoring inflammatory disease. Although measurement of serum $\mathbf{C}$ reactive protein is the test of choice within 24 hours of the onset of inflammation, ${ }^{3}$ the subsequent rise in plasma concentration of multiple acute phase proteins has traditionally been monitored by measuring the erythrocyte sedimentation rate. ${ }^{910}$ Plasma proteins of high molecular weight or frictional ratio, or both (fibrinogen, $\alpha_{2}$-macroglobulin and immunoglobulins) ${ }^{11}$ are largely responsible for increasing the erythrocyte sedimentation rate but they also increase the viscosity of plasma. Measurement of plasma viscosity as an alternative to measuring the erythrocyte sedimentation rate has not realised its potential, however, because of the lack of suitable automated instruments for use in clinical laboratories.

Plasma is a Newtonian fluid the viscosity of which is independent of shear conditions, and it can therefore be measured in a capillary system despite the high and 
variable shear stress across the diameter of the capillary. Use of a capillary system for an automated viscometer has the advantage that the surface tension artefacts of rotational viscometers are avoided. The ideal automated system for measuring plasma viscosity in clinical laboratories should include centrifugation of the blood to obtain plasma as this would further reduce the biohazard. With this limitation, the Viscometer II offers a useful automated measurement of the large molecular weight plasma proteins that are present in the later stages of the inflammatory response. This measurement has the important advantage, compared with measuring erythrocyte sedimentation, of being independent of the effects of haematocrit. Because plasma viscosity can be measured within 15 minutes, including centrifugation time, results can be made available to outpatient clinics and, because plasma can be stored at room temperature provided it has been separated from the packed erythrocytes, ${ }^{4}$ specimens sent by post can be tested. Laboratory quality control procedures for measuring plasma viscosity are also much simpler than for measuring erythrocyte sedimentation.

The Viscometer II performed satisfactorily as an automated instrument but quality control programmes should incorporate a check for accumulation of protein within the sampling valve. Although the present study did not include determination of reference ranges, these are likely to be identical to those determined by the selected method of the International Committee for Standardization in Haematology $\left(1.50-1.72 \mathrm{mPa} \cdot \mathrm{s}\right.$ at $25^{\circ} \mathrm{C}$, and $1 \cdot 16-1.33$ $\mathrm{mPa} \cdot \mathrm{s}$ at $\left.37^{\circ} \mathrm{C}\right) .^{7}$ Although plasma viscosity is independent of sex and largely independent of age,${ }^{12}$ the lower plasma fibrinogen concentration of the newborn ${ }^{13}$ and the higher plasma fibrinogen concentration of the elderly $^{14}$ indicate the need for further studies to determine more exact reference ranges at these extremes of age.
We thank Coulter Electronics for the use of a Viscometer II and Mr PCW Stone for technical advice.

\section{Refereaces}

1 Dinarello CA. Interleukin-1 and the pathogenesis of the acutephase response. N Engl J Med 1984;311:1413-8.

2 Stuart J, Whicher JT. Monitoring the acute-phase responselaboratory tests and clinical application. In: Delamore IW, Liu Yin JA, eds. Haematological effects of systemic disease. London: Grune \& Stratton (in press)

3 International Committee for Standardization in Haematology (Expert Panel on Blood Rheology). Guidelines on the selection of laboratory tests for monitoring the acute-phase response. J Clin Pathol 1988;41:1203-12.

4 Harkness J. The viscosity of human blood plasma; its measurement in health and disease. Biorheology 1971;8:171-93.

5 Hutchinson RM, Eastham RD. A comparison of the erythrocyte sedimentation rate and plasma viscosity in detecting changes in plasma proteins. J Clin Pathol 1977;30:345-9.

6 Lowe GDO. Blood rheology in vitro and in vivo. Baillière's Clinical Haematology 1987;1:597-636.

7 International Committee for Standardisation in Haematology. Recommendation for a selected method for the measurement of plasma viscosity. J Clin Pathol 1984;37:1147-52.

8 Harkness J. A new instrument for the measurement of plasmaviscosity. Lancet 1963;ii:280-1.

9 Faihraeus R. The suspension-stability of the blood. Acta Med Scand 1921;55:1-228.

10 Westergren A. Studies of the suspension stability of the blood in pulmonary tuberculosis. Acta Med Scand 1921;54:247-82.

11 Stuart J. The acute-phase reaction and haematological stress syndrome in vascular disease. Int $J$ Microcirc Clin Exp 1984;3:115-29.

12 Jung F, Roggenkamp HG, Ringelstein EB, et al. Effect of sex, age, body weight, and smoking on plasma viscosity. Klin Wochenschr 1986;64:1076-81.

13 Linderkamp O. Blood rheology in the newborn infant. Baillière's Clinical Haematology 1987;1:801-25.

14 Meade TW, Chakrabarti R, Haines AP, North WRS, Stirling Y. Characteristics affecting fibrinolytic activity and plasma fibrinogen concentrations. Br Med J 1979;1:153-6.

Requests for reprints to: Professor J. Stuart, Department of Haematology, The Medical School, University of Birmingham, Birmingham B15 2TJ, England. 